\title{
Autism, Inc.: The Autism Industrial Complex
}

\author{
Alicia A. Broderick \\ Department of Teaching and Learning, Montclair State University, \\ Montclair, NJ, USA \\ brodericka@montclair.edu \\ Robin Roscigno \\ Department of Educational Theory, Policy \& Administration, Rutgers \\ University, New Brunswick, NJ, USA \\ rfr42@scarletmail.rutgers.edu
}

\begin{abstract}
We contend that, within capitalism, the Autism Industrial Complex (AIC) produces both autism as commodity and the normative cultural logic of intervention in relation to it. Comprised of ideological/rhetorical as well as material/economic infrastructure, we argue that the AIC is not the myriad businesses and industries that capitalize and profit from it; rather, these constitute its epiphenomenal features. In the production of autism as commodity, the AIC also simultaneously produces that commodity's market, its consumers, and its own monopoly control of that market through production for consumption of need for, consent to, and legitimacy of interventionist logics. Within this apparatus, almost anyone can capitalize on and profit from autism. And within the AIC, autistic people - their very bodies — function as the raw materials from which this industrial complex is built, even as autistic people-their very identities and selves - also become unwitting, and often unwilling, products of the AIC.
\end{abstract}

\section{Keywords}

autism - capitalism - critical autism studies - neoliberalism - disability studies applied behavior analysis - autism industrial complex 
Dominant metaphors in popular, media, academic, educational, and policy rhetoric about autism for the last several decades have centered on the constitution of autism as enemy, abductor, epidemic contagion, alien, or otherwise dangerous and "other" (Broderick, 2010; Broderick \& Ne'eman, 2008; McGuire, 2016). These metaphors have been explicitly deployed in the service of a broader cultural narrative fueling "intervention" as the only sensible response to autistic people, effectively exploiting ableist hopes and fears in the symbiotic production of the commodities, markets, and consumers of the Autism Industrial Complex (hereafter, AIC) (Broderick, 2017; Broderick \& Roscigno, 2019). In the U.S., much of the "educational" provision for autistic students is provided by private schools and consulting firms, obviously profiting (mostly through receipt of public dollars) from the dominant cultural metaphors about autism and the interventionist narratives they sustain.

Autism narratives are being exported for global consumption through initiatives endorsed and financially sponsored by the United Nations and the ubiquitous "philanthropic" media behemoth Autism Speaks. State laws in the U.S. are being passed that funnel both private and public health insurance dollars straight into the revenue streams of behavioral consultancies, a business that has boomed in the 20 short years since the institution of the Behavior Analysis Certification Board (ВАСв) as a body that draws its principal revenue from the certification of multiple levels of behavior analysts. Autistic individuals (including now, very young children) collectively represent a vast market to be tapped and capitalized upon, a market for intervention "technologies" to be levied by certified "behavior technicians." There is money to be made in the certification of behavior analysts (both for ВАС В as well as for university-based programs who develoр в ввА programs and run them as cash-cow tuition-generating certificates, as well as for Pearson, who collects testing fees). There is money to be made in contracts with school districts - a steady stream of mostly public dollars: state, local, and federal IDEIA funding - to employ ABA consultancy firms (whose "technicians" are certified by the вАСв) to deploy these interventions in schools (thereby also exonerating districts from responsibility for altering the fundamental structure of their curricula, their pedagogies, their teacher preparation, or the cultures of their schools). And there is money to be made through health insurance reimbursement (also a steady stream of both private and public money, facilitated by the active state-level lobbying that has resulted, as of 2019, in the passage of boilerplate legislation in all 5o U.S. states constituting ABA as the "only" "evidence-based" and therefore only health-insurance-fundable, intervention for autism). 
In short, autism is currently big business.

Deploying both cultural and media studies and political economy as analytic frameworks, we argue that the multiple intersecting branches of the AIC constitute, reproduce, and globally export an effective monopoly not only of intervention services and products, but also (and more importantly) of ideas and information publicly propagated about autism over the past several decades. Ultimately, not everyone consumes autism intervention products and services, but it is difficult to escape the consumption of (a) autism itself as commodified and circulated in media and popular culture, and (b) its corollary interventionist cultural logic. The former market (in which autism intervention products and services are consumed) is somewhat narrow in its scope, but the latter market (in which autism, and the cultural logic of intervention are consumed) is pervasive and ubiquitous. And while the former comprises the autism industry, it is the latter that constitutes the AIC.

Central to our methods is an extensive critical analysis of language and its devices (metaphors, narratives, images, discursive tactics, etc.), ideologies and their power dynamics (claims to legitimacy and authority, and the deployment of "truth"), and the bureaucratic, technocratic, and-crucially-economic institutionalization of these ideas through the intersecting arms of the AIC apparatus under global neoliberal capitalism. This project makes a crucial intervention into autism discourse, currently rooted in rhetorics of care and recuperation (Helt et al., 2008), and material practices of bodily control and other forms of violence (McGuire, 2016; Roscigno, 2020). We seek to excavate the specific historical, ideological, and economic circumstances within which the AIC evolved, and in so doing, make the familiar-the routine monetization of autism - strange, and additionally, to develop an analytic sufficient to account for the present-day scale, profitability, and ubiquity of the AIC.

\section{Autism and Capitalism}

Relatively little scholarship in the past several decades has addressed the political economy of disability generally. Whole bodies of scholarship have critically explored, for decades and in various ways, the social and cultural production of disability; however, a few pieces distinguish themselves from that larger body of literature by documenting the simultaneous production of disability in a political economy-specifically, in the advanced neoliberal capitalist economy of the United States. A key early analysis of the economy of disability is Gary Albrecht's (1992) The Disability Business: Rehabilitation in America. In this comprehensive analysis of the rehabilitation industry, 
Albrecht candidly and explicitly explores the ways that disability became "big business" in the late 2oth century. His analysis explores the twin processes at work establishing the disability industry: (a) the "production of disability" as "the construction of a social problem," and (b) the rehabilitation industry as its "institutional response" (p.13). Marta Russell's selected writings (Rosenthal, Ed., 2019), posthumously published though produced largely in the 199os and early 20oos, offer an explicitly Marxist analysis of the political and economic role of disability in late 2oth century American capitalism. Russell's analytics include incisive discussions of capitalism's necessity of maintaining a reserve of untapped labor, structural inequality related to housing policy and disaster responses, and the role of incarceration relative to disability in a capitalist economy, among others. More recently, Paul Longmore's (2016) posthumously published Telethons: Spectacle, Disability, and the Business of Charity is perhaps the most comprehensive example to date of a complex analysis of the inextricably intertwined tendrils of both cultural politics and political economy-in this case, in the particular example of the telethon industry.

However, David T. Mitchell and Sharon L. Snyder (2015) have arguably advanced the most innovative theoretical contributions advancing a complex analysis of disability and neoliberalism, specifically, in their The Biopolitics of Disability: Neoliberalism, Ablenationalism, and Peripheral Embodiment. In developing the concept of ablenationalism, Mitchell and Snyder write that "disabled people are increasingly fashioned as a population that can be put into service on behalf of the nation-state rather than exclusively positioned as parasitic upon its resources and, therefore, somehow outside of its best interests" (p. 17). We will return to this notion of disabled people being put into service on behalf of the nation-state (and more specifically, its economy) as our own analysis develops.

These seminal works collectively offer foundational analyses of the intersections between capitalism and disability, generally. We are interested here in an analysis of the intersections between capitalism and autism, specifically. Both Albrecht (1992) and Longmore (2016) offer analyses of a capitalist political economy of disability that sit in intricate and complex relationship with incisive analyses of the symbiotic production and performance of the cultural politics of disability. In developing the analytic heuristic of the AIC, we offer herein an analysis of the co-constitutive production of both the cultural politics and the political economy of autism within capitalism.

The last 15 years have generated a vast and compelling body of critical scholarship exploring the cultural meanings of autism and autistic identity through multiple, intersecting, interdisciplinary lenses. These include feminism, cultural studies, sociology, linguistics, anthropology, rhetoric, queer studies, 
and others (e.g., Eyal, 2010; Jack, 2014; McGuire, 2016; Murray, 2012; Nadesan, 2005; Osteen, 2010; Rodas, 2018; Runswick-Cole et al., 2016; Silberman, 2015; Silverman, 2013; Yergeau, 2017). Most of these critical social and cultural analyses concur with the indisputable claim that autism is now big business- that much has been obvious for the past several decades. However, relatively little scholarship thus far has involved any analysis of autism in relation to the structures of our political economy, and none of those have yet put forth a comprehensive analysis that attempts to integrate critical social and cultural analyses with and through the overarching lens of political economy. Autistic scholar Michelle Dawson (2004) may have been the first to pinpoint and name the "autism/ABA industry" (n.p.) as such, and for the past 15 years, others have continued to describe and critically analyze what Milton (2012) calls the "vast and exploitative autism industry" (p. 3). Since Dawson's first articulation of ABA as an "industry," critical autism scholars have continued to write about the autism industry (Latif, 2016; Milton \& Moon, 2012), autism as commodity (Mallett \& Runswick-Cole, 2012, 2016), and autism as commodity fetishism (Goodley, 2016; R. Grinker, 2018; Mallett \& Runswick-Cole, 2012).

Anne McGuire appears to be the first to have committed to print the term "autism industrial complex," a concept articulated in "Buying time: The s/ pace of advocacy and the cultural production of autism" (2013), itself an incisive analysis of autism and time with/in the social and economic context of advanced neoliberal capitalism. In the closing paragraph of her analysis of the ways that autistic experience strains and threatens the boundaries of neoliberal concepts of time, McGuire notes that "we must take note of how neoliberal versions of advocacy...already represent a 'good' and very profitable 'return' on an awareness investment" (p. 121). Further, in pointing to the "sheer breadth of the 'autism industrial complex," she contends that "in one unbroken-and clearly very lucrative-move, our market-driven times, at once, produce and regulate, create and constrain conducts that are beyond the norm" (p. 121). McGuire further develops the idea of the autism industrial complex in her text, War on Autism (2016), though her discussion of the concept remains primarily descriptive rather than analytic. McGuire asserts that the "body of the autistic child has generated a multibillion dollar 'autism industrial complex'-public and private investment interests that benefit economically from, and indeed whose very fiscal survival is reliant upon, the existence of" autistic bodies (p. 126). Consistent with her stated intent "to provide the reader with a sense of the immensity and diversity of the autism industry," (p. 127), McGuire points to the industry of jobs and institutions whose purpose centers primarily upon autism intervention. She notes that "whole industries have cropped up around treating and/or curing autism," while "other industries have discovered 
it can also be profitable to take the prevention route," while still "other industries...have honed in on the autism niche market" (p. 127), including products such as software/apps, toys, books, communication aids, etc..

Other critical autism scholars have subsequently drawn upon this concept in analyzing the economics of autism (Broderick, 2017; Grinker, 2018, 2020). Grinker (2020) argues that this "particular diagnosis [autism] became embedded in a financial system that has come to depend on that diagnosis for its sustainability and growth" (p. 7). Further, building upon Ian Hacking (1999), Grinker argues that once a diagnostic label—such as autism—becomes a fulcrum around which institutionalized financial activities coalesce (i.e., once an industrial complex is formed), that very diagnostic category "provides an incentive for manufacturing people with the diagnosis...whose presence and needs support this financial infrastructure" (p. 9), effectively rearticulating Mallett and Runswick-Cole's (2016) contentention that autism has been successfully commodified. Broderick (2017) argues that autism rhetoric (including deployment of the metaphors of alien, invader, epidemic, enemy, etc.) has been central to that commodification process-the manufacturing of autism, and thereby, through processes of interpellation, autistic people-all in the service of manufacturing a broader cultural narrative or logic of intervention, thus producing the market for, and teleologically justifying and sustaining the profit-generating infrastructure of, the autism intervention industry.

Two edited collections published over the past decade have worked to establish the foundations and contours of the emergent field of critical autism studies (CAS), and each of these has engaged somewhat with questions of political economy, but to a limited extent. The first, titled Worlds of Autism: Across the Spectrum of Neurological Difference (Davidson \& Orsini, 2013), actually coined the term critical autism studies and developed a loose conceptual framework of what CAS comprise. These include: 1) careful attention to the ways that power shapes our understandings and study of autism, 2) the advancing of empowering cultural narratives about autism, and 3) a "commitment to develop new analytical frameworks using inclusive and nonreductive methodological and theoretical approaches to study the nature and culture of autism" (Orsini \& Davidson, 2013, p. 12). Thus, the import of studying narrative, culture, and specifically, power is placed front and center in this articulation of the aims of CAS as a field of critical scholarship, although economics is not explicitly invoked.

Nevertheless, as economics is a central mechanism through which power circulates, within this edited collection a couple of manuscripts do engage with the economics of autism, albeit in limited ways. For example, Nadesan (Nadesan, 2013) presents an analysis titled "Autism and genetics: Profit, risk, 
and bare life." Nadesan, whose earlier (2005) comprehensive sociocultural analysis of autism as a construct appeared to spark the wave of critical scholarship on autism that has been produced over the past 15 years, writes in this piece specifically of the social and political processes of assessing and managing the "economic risks" (p.117) associated with autism. Through an analysis of the prioritization of funding related to autism (including allocations of public funds toward research, pharmaceuticals, and the quest for genetic markers that may yield either pre- or postnatal tests for autism), Nadesan raises difficult questions about the ratio of public dollars spent on care and support vs. basic research ultimately aimed at prevention of autism. In the context of neoliberal austerity measures, Nadesan warns that "Family members of people with autism will be 'responsibilized' for their care without the benefits of supports as states, counties, cities, and school districts shed services" (p. 134). Additionally, Nadesan somewhat ominously predicts that the prioritization and investment of funding in autism susceptibility testing may "have the potential of refiguring risk so that parents of autistic children are made financially responsible for the 'choice' to keep (that is, not abort) their autistic children" (p. 134), and that "this prioritization could undermine support for costly educational and therapeutic supports" (p. 137). In this same volume, Bumiller (2013) critically analyzes the politics and economics of the increasing privatization of responsibilities of care in a neoliberal economy, arguing that "it is necessary to reimagine the [financial] responsibilities of the state in the hope of creating a more socially inclusive future for people with autism" (p. 145). Both of these forays into the political economy of autism fundamentally circulate around the costs of intervention, care, and support, and whether those costs should be socialized or privatized, rather than critically examining the intervention industry itself.

In a second edited collection (Runswick-Cole et al., 2016) aiming to contribute to the nascent field of CAS, only a couple of pieces refer-and most of those somewhat tangentially-to the import of economics in the critical study of autism. In the introductory chapter, Runswick-Cole (2016) asserts the problematic nature of the commodification of autism (see also Mallett \& Runswick-Cole, 2012, 2016): "This thing called autism is everywhere" (p. 25, emphasis in original). She further acknowledges that "Clearly, there is money to be made in autism" and cogently, that "it is not possible to comment on the autism industry without contributing to it" (p. 26). Nevertheless, few of the manuscripts in the collection explicitly analyze this autism industry, though a number concede its profit-generating existence as taken-for-granted background of their analyses. For example, Goodley (2016) refers briefly to multiple forms of "commodity fetishism around autism" (p. 156), and McGuire (2016) parenthetically notes that "the notion of spectrum offers a hopeful (which, 
from the vantage point of capitalism, most often means lucrative) narrative of the possibility for an incremental recovery of normative life" (p. 103). Further, Timimi and McCabe (2016) rather obliquely, and almost as an aside, quip that "To us, however it seems that the people who have most obviously benefitted from the increase in the use of tools for screening for and diagnosing of ASD $s$ have been the professionals themselves" (p. 173).

Latif (2016) engages with these issues somewhat more explicitly. Although his analysis is largely centered on ethical deliberations around autism diagnoses, that discussion is squarely framed within the context of neoliberal austerity policies as a sort of backdrop for the ethical analysis. Latif principally aims to explore how people's ideas about autism "are modified and influenced by the dominant classification systems, which in a capitalist market has been driving toward a technically based biomedical model of mental wellbeing" (p. 288). Latif further notes that "whilst such a model may be good for expanding markets, problems of feeding disproportionate demand against limited resources arise in universal public health systems such as the United Kingdom National Health Service (NHS)" (p. 288). This primary concern with scarcity of resources in general, and with the impacts of neoliberal economic policies of privatization and austerity in particular, align Latif's, and most of the analyses of economics in this volume, with those in the Davidson and Orsini (2013) collection.

Mallett and Runswick-Cole (2016) offer the only contribution to this volume to explicitly advance an analysis of autism within capitalism in their piece, "The Commodification of Autism: What's at Stake?", wherein they argue that "autism has become a commodity; it is produced, exchanged, traded and consumed" (p. 110). These authors contend "it is the moment when it [autism] becomes a 'thing' that it becomes consumable and, therefore, amenable to commodification" (p. 117). They successfully argue and amply demonstrate in this piece that autism has become a hot commodity, illustrated with cogent examples of autism therapies, entertainment and popular culture, and even the rebranding efforts of the neurodiversity movement. However, neither Mallett and Runswick-Cole (2016) nor any other extant analyses yet demonstrates how autism came to be successfully commodified, nor the nature of the intersecting social, historical, cultural, political, and economic infrastructures that both produce and sustain it as a lucrative commodity.

This analysis aims to do just that. Multiple authors have offered useful descriptions of the nature and range of the profit-generating marketplaces operating in the AIC - e.g., not only intervention services, but diagnostic and evaluation services, scholarship and research industries, media industries, the special education and related services industries, niche technology industries, 
etc. (Grinker, 2020; Mallett \& Runswick-Cole, 2016;McGuire, 2013, 2016). Almost all extant analyses of autism and neoliberal capitalism focus on the societal and personal implications of privatization and austerity, vis-à-vis access to intervention products and services. Or as Grinker (2020) puts it, exploring the challenges parents face "as they seek to find services and social supports that will enable their diagnosed children to be educated and launched into the neurotypical world" (p. 8). However, to date, no one has yet developed a comprehensive conceptual analytic of the cultural and historical contexts in which the AIC emerged, nor how the AIC operates in the overlapping spheres of both cultural politics and political economy, manufacturing not only the commodity of autism itself, but also, and crucially, the cultural logic of intervention that undergirds the entirety of the AIC's economic infrastructure.

We develop and deploy the AIC as a useful heuristic device that enables us to document and critically analyze the intersecting spheres of both cultural politics and political economy in the simultaneous cultural and economic production of autism and the cultural logic of intervention in relation to it. Our analysis aims to hearken back to Albrecht's (1992) in that we aim to braid together a complex analysis of (a) the production of autism as a "social problem" with (b) the institutional (interventionist) response to that "problem." That is, we explore the ways in which the cultural politics of autism and the economy of autism co-constitute one another. In so doing, we draw upon and weave together analyses of the intersecting strands of ideology, rhetoric, and discourse, together with the interlocking strands of social policy, business, education, and medicine, all of which collectively serve to generate and to justify further extraction of profit from autism - and therefore autistic people - in an advanced neoliberal capitalist economy.

Since Eisenhower first burned the concept of the military industrial complex into the public imagination in his now-iconic warning in 1961, the notion has been extrapolated to many different spheres of culture, society, and government. No matter the context, these extrapolations implicitly evoke Eisenhower's urgent claims: that "we must guard against" the potential for the "disastrous rise of misplaced power," forever latent (if not actualized) in association with entrenched profiteering and ideological monopoly (Eisenhower, as cited in Picciano \& Spring, 2012, p. 1). We'll briefly index here two extant extrapolations of this concept relevant to our development of the heuristic of the AIC: (a) the medical industrial complex (Ehrenreich \& Ehrenreich, 1970; 
Mingus, 2015), and (b) the education industrial complex (Picciano \& Spring, 2012).

An early and obvious extrapolation of the idea of the military industrial complex was the articulation of the analogous medical industrial complex (Ehrenreich \& Ehrenreich, 1970), more recently further conceptually developed by Mia Mingus (2015). Mingus proposes a fluid and dynamic fourpronged interlocking web of sectors, comprising the sectors of science and medicine, health, access, and safety, further articulating corresponding and underlying motivations or drivers of these sectors: eugenics, desirability, charity and ableism, and population control. Within these overlapping sectors, and driven by these overlapping cultural ideologies, values, or motivators, Mingus articulates some of the major profit-generating components of the medical industrial complex, such as the pharmaceutical and mental health industries, medical schools, insurance companies, and the prison-industrial complex and nursing home industries. Mingus's conceptual framework is at once complex and dynamic, and indicative of a rapidly evolving marketplace in relation to a relatively stable underlying economic and ideological architecture.

Another obvious extrapolation from the concept of the military industrial complex is that of the education industrial complex: Picciano and Spring (2012) outline a thesis detailing the rise of what they call "the great American education-industrial complex," defining it as

networks of ideological, technophile, and for-profit entities that seek to promote their beliefs, ideas, products, and services in furtherance of their own goals and objectives. This complex is fueled by significant resources and advocacy provided by companies, foundations, and the media that want to shape American education policy to conform to their own ideals and that also stand to profit significantly from its development. (p. 2)

Substitute "autism" for "education" in this definition and you have a cogent description of the AIC. Picciano and Spring's analytic is a much simpler heuristic than Mingus's, comprising principally the tripartite intersecting components of ideology, technology, and profit. Central to Picciano and Spring's heuristic is the intersections of networks of entities that seek not only to promote their products and services in order to generate profit, but that simultaneously seek to promote their ideas and beliefs (which is just as central to the ultimate goal of generating profit). Autism as commodity is produced and consumed in part through the mobilization of both the medical- and educationindustrial complexes, and the specific exploration of the AIC has the potential 
to further explicate and illuminate how both underlying industrial complexes function. Without endeavoring to reconcile or collapse these two divergent conceptual frameworks into one, we will nevertheless note that in the case of the AIC, multiple intersecting and networked sectors of the economy are implicated in the simultaneous production not only of technologies (products and services), but also of ideologies (concepts, values, beliefs, and cultural narratives), that are jointly marketed, produced, and distributed for consumption, all in the ultimate service of profit generation.

Indeed, Picciano and Spring (2012) point out the centrality of these networks to the economic operation of the educational industrial complex, noting that it

is not simply a single entity conspiring to influence education policy. In fact, it is made up of multiple networks that sometimes share agendas but frequently operate independently and compete with one another for contracts and sales of goods and services. (p. 2)

As is the case with both the medical- and educational-industrial complexes, these networks of entities that comprise the AIC are loose and overlapping, and in many ways have emerged over decades as an ad hoc apparatus that is distinctly different from a planned, coordinated, orchestrated monolithic entity. This paper does not afford the time or space necessary to fully outline each of the plutocratic players in the neoliberal networks of the AIC, nor to fully outline and analyze the rhetorical and ideological evolution of the AIC. Mapping the historical emergence and retrenchment of the AIC is part of a larger (book-length) project. However, in lieu of that (Broderick, forthcoming) analysis, we offer here an abridged composite narrative of the emergence of several main "players" on the autism scene, coupled with brief illustrations of their emergence further solidifying the foundations of AIC as described.

Among these overlapping and intersecting authorities operating in the AIC marketplace are at least four different networks of players, each of which is intimately connected with the field of behaviorism, generally, and with the field of Applied Behavior Analysis (ABA), more specifically. These include: (a) academic behaviorists (Ph.D.s in behavioral psychology, teaching at institutions of higher education and publishing studies and position papers in peer-reviewed scientific journals); (b) nonautistic parents of autistic children; (c) the Behavior Analyst Certification Board (ВАСв) (a private, non-profit corporation established in 1999 that certifies behavior analysts [Board Certified Behavior Analysts, or всвAs] at multiple levels); and (d) Autism Speaks (self-described as the world's largest scientific and advocacy organization for 
autism; described here as a global, multi-platform, neoliberal media organization and corporate-style policy lobbyist). These players anchor a network of interrelated ventures, and together comprise the foundational plutocrats of the AIC, each of which currently participates in some way in the commodification of autism, as well as the concurrent manufacture and branding of its market through producing interventionist logics for public consumption. In so doing, each of these component networks also participates in the commodification of autistic bodies and the production of autistic identities.

As Eisenhower warned, at any time that power is consolidated in the hands of a few, we must guard against its potential abuse. Eisenhower saw inherent danger and hidden costs in the tempting profitability of the military industrial complex - he feared that the industry would be driven not by the interests of national security, but rather by the interests of private and corporate profitability. He also feared that the human costs of military proliferation would be regarded as insignificant in the face of its profitability. Likewise, we fear (and assert) that the AIC is driven not by the interests of autistic individuals but by the interests of those who stand to profit from the AIc. Additionally, we contend that the costs to autistic people of the proliferation of the AIC have generally been regarded, thus far, as insignificant in the face of its profitability.

Eisenhower specifically warned of the dangers of our national military functioning as a profit-generating sector of the economy, foreseeing the vast potentials for corruption, consolidation of power, and above all, profit superseding national security as the central driver of decision-making. Arguably, the rise of the military-industrial complex was an inevitable development in late 2oth century American capitalism. So too, was the subsequent consumption of the economic sectors of health care (by the health insurance and pharmaceutical industries), education (by the textbook publishing and testing industries), and public safety and criminal justice (by the prison industry), among myriad other sectors of our economy that arguably should never be driven by the extraction of corporate or private profit. Most of the early descriptions of the AIC largely focus on documenting the actual profit-generating infrastructure (e.g., the sale of intervention services, products, etc.) as the presumed architecture of the AIC. We contend that those products (whether they be goods or services) that are literally being bought and sold-through financial transactions that are generative of profit - are actually epiphenomenal features of the AIC, and are better described as components of the autism industry. They better enable us to perceive the existence of the AIC, and they are, in effect, suspended by its structures, but they do not in themselves comprise the AIC, nor do they constitute its most salient or foundational products. 
We concur with Mallett and Runswick-Cole's (2016) assertion that autism has been successfully commodified, and we argue that the central product manufactured and consumed in the AIC is the commodity of autism itself. However, although Mallett and Runswick-Cole $(2014,2016)$ center much of their discussion on autism knowledge as commodity, we are compelled to reiterate that autism does not merely exist as an idea in a disembodied epistemological state, being bought, sold, exchanged, and consumed in an abstract market. Rather, autism is a construct inscribed upon, experienced through, and materialized by the bodies of autistic people, and we concur with McGuire's (2016) assertion that the multibillion dollar AIC generates industries "that benefit from, and indeed whose very fiscal survival is reliant upon, the existence of" not merely autism as a concept, but autistic bodies (p. 126, emphasis ours).

While neoliberal capitalism without question undergirds the entirety of the AIC, a more specific ideology also drives the particular historical circumstances of its emergence and development, one that (unlike capitalism generally) has its very own proprietary technology: the ideology of operant behavioral psychology, and its associated technologies of applied behavior analysis (ABA). It has been the deployment of behaviorism as an ideology-driven through its applied technologies of $\mathrm{ABA}$ - that has enabled the development of a large-scale and complex technocratic infrastructure for generating profit from autism over the course of the last seventy-five years. And the specific ideology of operant behaviorism, added to the ideology of neoliberalism, has profoundly shaped the second central ideological product manufactured and consumed in the AIC: the cultural logic of (behavioral) intervention.

This analysis attempts to excavate the particularities of the historical entanglements among autism, operant behaviorism, and capitalism as they emerged in the mid-late 2oth century and persist today. We argue that behaviorism happened to be implicated in the foundational structures of the apparatus of the AIC because of serendipitous historical circumstances wherein behaviorism was contemporaneously ascendant with the ascent of autism as an ontological category, and with the rapid development and ascendance of global neoliberal capitalism generally. However, the role of behaviorism could just as easily have been played by Freudian psychology (a decade or two earlier), or brain-based neuroscience (a few decades later). The heuristic of the AIC enables us to critically examine the ways that ideology and cultural politics fluidly and dynamically evolve as capitalism evolves, and we must understand both in relation to each other and to autism as a historically specific ontological category. The work of the industrial complex consists in imbuing the ontological category of autism with particular cultural meanings 
and significances, and in further transforming that ontological category into a successful commodity through a range of manufacturing, salvaging, extraction, and branding efforts. Additionally, the industrial complex manufactures its market and its consumers (producing need, grooming consent, creating consumers, and manufacturing legitimacy) through producing for mass consumption the cultural logic of intervention. The central "problem," from this perspective (if pressed to identify just one) is less behaviorism than it is capitalism.

\subsection{What are They Selling You? Autism Within Capitalism}

Wang (2018), in an incisive analysis of the debt economy in her seminal text, Carceral Capitalism, asks, when predatory lenders are targeting consumers for "opportunities" to open lines of credit, and consume other forms of product derived from the commodity of debt, "what are they selling you?" (p. 32). Financial institutions engaged in these practices, she argues, "are selling you indebtedness itself" (p. 33). We expand McGuire's initial conceptualization of the AIC by asking the simple question, when the AIC is manufacturing its products for consumption, "what are they selling you?" Yes, intervention services are being produced and consumed. For the most part, they are being produced by professions and occupations that didn't exist a century ago-behavior therapists, speech and language therapists, occupational therapists, special educators and paraeducators, play therapists, legal firms specializing in autism-related litigation, etc.. And they are being consumed mostly by the non-autistic parents of autistic children procuring those services for their children, and the public school districts charged with educating those children. In the autism economy, the individual products being bought and sold—-the therapies, the books, the "awareness" t-shirts, the fidget spinners, the myriad interventions and services-constitute the autism industry. But a vast deal more than these products is being consumed in the AIC. What else are they selling us? In addition to (and arguably obscured by) these epiphenomenal products and services that are literally being bought and sold to the tune of billions of dollars annually in the AIC, we contend that the central product that the autism economy is producing and marketing for public consumption-in effect, "is selling you"-is autism itself, and that the integrally intertwined, complementary constituent product — that the AIC "is selling you" — is the cultural logic of intervention.

A crucial analytic framework that we bring to bear upon our analysis of the AIC stems from Wang's critical analysis of carceral capitalism—specifically, her conceptual expansion of Marx's notion of the lumpenproletariat. In Carceral Capitalism, Wang describes the political economy of the prison system. She 
draws on Marxist political theorist Rosa Luxemburg to describe how capitalist accumulation adapts to changing forms of capitalist production and consumption. In her expansion of Marx, Wang argues that Marx assumes that the proletariat are incorporated into the capitalist system as waged laborers. However, due to rapid technological advancement in production, this is no longer so and "segments of the workforce are also regularly shunted from the process of production." (p.109). Wang contends that "This process continually opens up new domains for expropriation and value generation, whether it is through money lending or warehousing people in prisons" (p. 109). Debt, she argues, is a means for those dispossessed of wage labor to consume, what Marxist geographer David Harvey terms "accumulation by dispossession" (Harvey, 2003, p. 154). She describes Marx's lumpen class - the unemployed - as having a dual function. The first function-Marx's conceptualization-is to create a class that is available to work, workers without work, that function as a labor reserve that drives down wages and prevents unionization. Wang builds on Marx's analysis to articulate a second function of the lumpen class. Wang argues that lumpenproletariat are also integrated into the consumer class (usually reserved for wage laborers) by the acquisition of debt and consumption vis-a-vis borrowed money.

We contend that the AIC is another mechanism by which the lumpen class (the unemployed) are integrated into consumption. Disabled people are underemployed (Persons with a Disability: Labor Force Characteristics-2019, 2020 ) and, depending on the nature of one's disability, may not enter into the economy as a wage laborer. However, much like the acquisition of consumer debt, autistic individuals are constructed as possessing a born indebtedness through the rhetoric of the AIC. The debt here is educational, therapeutic. And estimates abound as to the cost of this educational and therapeutic debt. Grinker (2020) notes that "Buescher et al. (2014) estimate that for the United Kingdom, the average lifetime cost of care for a person with autism is $\$ 1.4$ million; Leigh and $\mathrm{Du}$ (2015) estimate that by the year 2025 the total national cost in the United States for caring for people with autism will exceed $\$ 461$ billion per year" (p. 7). But this is when autism goes to work. Grinker (2018) notes that, "Paradoxically, autism is at once a threat to economic growth and (at least for many parts of American society) an engine of economic growth" (p. 244). We contend that it is not truly paradoxical. The former narrative (the high "cost" of autism) serves a necessary role in shoring up the justification for the extraction of profit from the autism industry (thus, this apparent "paradox" we argue is but two sides of the neoliberal coin).

Mitchell and Snyder (2015) argue that in a neoliberal political economy, "disability has been transformed into a target of neoliberal intervention strategies" 
(p. 205). Further, they argue that, " $[\mathrm{r}]$ ather than a former era's economic 'burden,' disabled people have become objects of care in which enormous sectors of postcapitalist service economies are invested" (p. 205). And although Mitchell and Snyder posit that the notion of "burden" belongs to a former economic era, we argue that rhetorically, the presentation of autistic people as potential future economic burdens continues to be trotted out as a justification for participation in and consent to the intervention industry (in which a fair amount of profit is systematically extracted from autistic people). The net amount of therapy needed to bridge the gap to wage laborer/consumer becomes a means of consumption, thus integrating the lumpen class of disposed and dispossessed autistic citizens into the realm of consumption as consumers of intervention. Or, as Mitchell and Snyder contend, the economic relations of ablenationalism situate disabled (in this case autistic) bodies "in a position tantamount to un(der)explored geographies: they come to be recognized as formerly neglected sites now available for new opportunities of market extraction that fuels so much of the production end of neoliberal capitalism" (p. 206).

And unlike Marx's original concept of the lumpen class, in the case of autistic people, it is not merely those of age to be potential (albeit "failed") wage earners that are targeted through these mechanisms. Rather, through the processes of dispossession, children as young as two years of age are economically mobilized as raw material to be extracted and capitalized upon, even as their parents and schools are integrated as consumers of intervention, enacted upon the bodies of their autistic children. We argue here that the massive scaling up of the scope of the AIC is in no small part dependent upon the successful braiding together of the cultural political and economic architecture such that non-autistic adults (primarily parents of autistic children, adult teachers and school administrators, etc.) were groomed as the AIC's targeted consumers of autism (and therefore, its complex of interventions). This circumstance has engendered not merely the commodification and consumption of the idea or the concept of autism, but more perniciously, of the commodification and consumption of autistic bodies, including the bodies of very young children, in the generation of profit for these intervention industries.

Essentially, we argue that the AIC is not an anomaly, an aberration, or a corruption of the meanings or materialities that autism "should" have; indeed, we argue that within late 2oth century American neoliberal capitalism, the AIC couldn't not have developed. It might have developed slightly differently if specific historical and cultural circumstances had unfolded slightly differently (20 years earlier, its foundational disciplinary foil may have been Freudian psychology; 20 years later, it may have been brain-based neuroscience), but essentially, 
within neoliberal capitalism, there had to develop, and will undoubtedly continue to be, an AIC. We have been heartened and intellectually nourished by the last decade and a half of critical autism scholarship (e.g., anthropological, sociological, literary, rhetorical, feminist, queer, etc.), including the birth of a subfield of academic inquiry dedicated to it (CAS). However, we simply cannot proceed further with our own critical scholarship on autism without a systematic and comprehensive exploration of the intersections of neoliberal capitalism and autism, and the ways that the former has been constitutive of the latter (virtually from its conception).

\subsection{What are they Selling you? The Cultural Logic of Intervention}

The AIC couldn't thrive as it has if it merely produced the commodity of autism; it also manufactures a normative and narrative cultural logic - the cultural logic of intervention. Thus, encompassed within the production of autism for public consumption is the simultaneous manufacture for consumption of the constituent rhetorical products of (a) both need for and consent to intervention for autism and (b) claims to the legitimacy of particular intervention technologies. These constituent rhetorical products work in tandem with the production of autism as commodity to produce for widespread consumption the narrative logic that not only is autism dangerous, threatening, and generally bad, but also that it therefore necessitates intervention and that certain forms of intervention are more legitimate than others.

The cultural logic that produces both need for and consent to intervention for autism is manufactured through the systematic deployment and manipulation of both cultural fears and cultural hopes, in crafting hegemonic cultural narratives that autism (of course) necessitates intervention. The primary mechanism creating this market for the industrial complex of interventions is currently a wide-ranging, sophisticated, multi-platform, ubiquitous, and global media campaign-you name it: social media, television, magazines, newspapers, television talk shows, talk radio, public service announcements, celebrity-sponsored fundraising concerts and other events, government and policy documents and rhetoric, etc.. However, the foundational labor of producing this market began with academic behaviorists, and later included non-autistic parent advocates before being scaled up to include global media campaigns and the ABA intervention services industry itself. We'll additionally note that this media campaign — and its earlier waves of academic and parental advocacy - integrally comprises a strong sense of cultural urgency (e.g., autism is a "emergency," it's an "epidemic," it's a "tsunami," etc.) in its establishment of need, thereby simultaneously facilitating and streamlining widespread consent to participation in the intervention industry. And from 
the very inception of what can only be understood as a large-scale marketing and branding campaign, the rhetorics of both hope and of fear have been systematically deployed in purposeful, effective, and largely successful ways (Broderick, 2009; Broderick, 2010; Broderick, 2011).

An additional constituent rhetorical product manufactured within the cultural logic of intervention itself is the AIc's own legitimacy (both "scientific" legitimacy through the strategic deployment of scientism as rhetoric, as well as "professional" legitimacy, established through the professionalizing discourses and centralized certification infrastructures of the ВАСв). The rhetoric of positivist science has been absolutely central to the AIC's branding campaign from the beginning, serving as a foundational argument for ABA's monopolizing of the economic architecture to follow. Subsequent to the emergence of that economic architecture, in many ways the profit-generating apparatus itself has served as a further, teleological constitution of legitimacy: We offer intervention products and technologies, we only recognize our own intervention products and technologies as "evidence-based," we have ensured through policy lobbying that funds will flow toward our intervention services granting us dominant market share if not monopoly status; therefore, we also have market legitimacy. Through the intertwined architectural arms of scholarship, policy, and popular culture/media, both the privatization of intervention industries and the simultaneous corporate-style globalization of "advocacy" and philanthropy emerge as monolithic, politically "neutral," "legitimate" —and importantly—profit-generating establishments.

\subsection{What are they Selling you? Autistic Identity}

A final, symbiotic rhetorical and material product of the AIC that simply cannot be separated from the AIC's production of autism as commodity and its corollary interventionist logic is the production of the very identities of autistic people. The AIC itself is parasitic upon the bodies of autistic people; it cannot exist without autistic people, who are often exploited as unwitting or unwilling raw material for profit extraction in the industrial complex, particularly when those bodies are the bodies of very young autistic children. Through biopolitical technologies of control and virtually propagandist monopolies of ideas, the AIC actively constitutes what it means/is to be autistic within global neoliberal capitalism. It is important to note that this third constituent product of the AIC is integrally intertwined and performed with/in each of the first two. Indeed, we argue that one can't engage in the production of any one of these three without effectively engaging in the production of the other two. For example, in the manufacturing of need for the AIC, and thereby the grooming of consent to it, identities are simultaneously being forged through powerful processes that transform and interpellate individual subjectivities. 
Within the cultural politics and political economy of the AIC, autistic people are manufactured as autistic identities are interpellated through specific cultural and media representations and productions of autism, coupled with biopolitical technologies of surveillance and control. Similarly, when the AIC is rhetorically manufacturing the need for its own economic architecture (intervention products, technologies, services, etc.) through the propagation for popular cultural consumption of heinous ideological metaphors about autism as enemy, predator, alien, epidemic, tsunami, caravan, etc. (insert dangerous and urgent metaphor of the month here), identities are simultaneously being marketed for consumption. Autistic people are integrated into consumption through their function as the lumpenproletariat class that forms the economic foundation of the intervention industry. What are they selling you? A cynical, bigoted, culturally devalued notion of autism itself, and therefore, of being autistic. A significant difference in this instance is that autistic people are not the primary consumers targeted in the AIC marketplace-non-autistic people (both parents and potential parents of autistic children) are.

This analysis represents a significant departure from other Critical Autism Scholars' analyses of autism within capitalism, many of which appear to accept the naturalness of the intervention industry itself and most of which primarily situate their critiques within neoliberal austerity policies and concerns about scarcity of intervention resources. For example, Mallett and Runswick-Cole (2016) warn us of the potential of autism to be made "useless" and to be subject to the whims of the market, with the loss of support services being collateral damage. We contend that the AIC is actually itself abundantly generative, not an arbitrary vessel for surplus value; rather that the AIC consumes through constructing autistic people as fundamentally, infinitely indebted. Together, the AIC's production and commodification of both autism as an ontological category and the cultural logic of intervention in relation to it have been structuring our ideas and conceptualizations about autism, our access to dissenting information about autism, and effectively limiting the range of our responses to autism through flooding the marketplace of ideas with the monopoly of intervention in general and $\mathrm{ABA}$ intervention in particular, for more than seventy-five years.

\section{Discussion: With/in (and With/out?) the Apparatus of the AIC}

Very often, at this point in academic manuscripts, the authors close with nebulous calls to action that purport to be radical and transformative (i.e., urging readers to "dismantle" or "deconstruct" oppressive institutional structures), 
but that more often than not are ultimately unhelpful, ineffectual, and even grounded in fanciful thinking. Let us be clear: In excavating this particular history, we are not suggesting that there is any simple, straightforward, transformative, or revolutionary alternative to the AIC. We are not interested in creating an alternative enemy. We are not trying to ban behaviorism (as others have suggested in more activist spaces) (Sequenzia, 2016). We are not calling for revolution or for the systematic dismantling of behaviorism, of capitalism, or indeed of anything. As a pure thought experiment, entirely removing behaviorism from the mix still leaves: autism and capitalism. This, we argue, is (and will continue to be) the crux of the matter.

So-is it even possible to operate outside of, beyond, in active subversion of capitalism? Mitchell and Snyder (2015) argue not outside of or beyond, but offer their excavation of biopolitics to generate subversion of or even insurgency against neoliberalism: "Rather than posit a space outside of neoliberal capitalism, the biopolitics of disability explores how forms of dissent evolve within limiting rubrics of neoliberal diversity" (p. 219), or what they refer to as "forms of insubordination within global capitalism" (p. 206). And just as the distributed networks of the AIC are ad hoc, loosely affiliated, and sometimes even operate in competition with one another, so, too, we argue are the possibilities for collective - albeit non-unified — forms of dissent exercised with/in, and even with/out, the AIC.

We cannot help but evoke in this moment the image and the example of the matsutake mushroom explored in glorious, rich, complex, and nuanced detail by Anna Lowenhaupt Tsing (2015) in her brilliantly rendered The Mushroom at the End of the World: On the Possibility of Life in Capitalist Ruins. Tsing's text is a multispecies anthropological study of Matsutake mushrooms and the strange underground economy around their cultivation, collection and distribution. The Matsutake is a rare and valuable aromatic mushroom whose defining features are the ability to grow within and among various detritus and an economy built by those often marginalized by traditional markets-foragers. Tsing's text provides a rich case study of how to both exist within the confines of late-stage capitalism, and to resist capitalism as a totalizing, grand narrative in order to find possibilities - in the case of the Matsutake foragers, a life in the woods that evades some of the traumas of mainstream society. Tsing describes how Matsutake gathering is a project of collective survival, and argues that unintentional coordination develops as an assemblage, one that is both contaminated and polyphonous.

We offer in closing three brief, diverse, possible, polyphonic (that is to say, both harmonic and dissonant) examples of survival with/in (and possibly with/out?) the AIC, in the limiting rubrics and even the ruins of neoliberal 
capitalism (which is not to say after capitalism, but rather, within it and pervading it and despite it).

First, we call attention to the daily, corporeal resistances that occur in the various spaces of containment within the AIC: the clinic, the group home, the school, the therapy practice. I (second author) have plotted some of these resistances found within the corpus of ABA scholarship (Roscigno, 2019). Specifically, we are talking about the "head-bangers," "biters," "runners," and "shit-smearers" that slow the AIC through their physical resistance, even when such resistance is not complete, cogent, or part of some larger activist program. Tsing characterizes such activity as a "latent commons" (p. 255) which she describes in the negative, "latent commons don't institutionalize well," stating "[a]ttempts to turn the commons into policy are commendably brave, but they do not capture the effervescence of this latent commons. The latent commons moves in law's interstices; it is catalyzed by infraction, infection, inattention,- - and poaching" (p. 255). These temporal, bodily resistances form a latent commons that allows for resistant activity outside of grand, redemptive progress narratives.

Secondly, we recognize the importance of the Neurodiversity/Autistic Pride movement in forging an important coalition and site of resistance. The Neurodiversity movement has made material gains for autistic people in education, health care, employment, housing, etc. through public education, advocacy and policy work. Organizations such as the Autistic Self Advocacy Network (ASAN) and Autistic Women and Non-Binary Network (AWN) have helped to bring attention to autistic people as a marginalized group and to usurp some of the power of parent and professional organizations. Arguably the most important contribution of the Neurodiversity movement has been creating a language, platform and infrastructure to help autistic people find one another, organize, commune and to create vital support networks outside of the AIC. Mutual aid projects such as the Fund for Community Reparations for Autistic People of Color's Interdependence, Survival, and Empowerment organized by Lydia X.Z.Brown, Morénike Giwa Onaiwu, Sharon daVanport and Sara María Acevedo have provided important survival resources for autistic people and thwart the AIC's aims of extracting as much capital as possible from autistic people, instead directing capital towards autistic people.

Lastly, and perhaps in closest evocation of Tsing's matsutake mushrooms, are the collective of autistic people who (wittingly or unwittingly) successfully evade the apparatus of the AIC by either (a) operating under the radar or in "stealth mode" within the educational and medical industrial complexes themselves, or (b) operating "off-grid," which is to say more or less outside of the formal education and medical industrial complexes. The former may be 
described as a form of disidentification, and may potentially be critiqued as "passing" by some of those who are invested in the utility of a disabled/nondisabled or autistic/allistic binary. Nevertheless, such disidentification can just as easily be borne of a cynical assessment of the possibilities of (and indeed, the limitations of identity politics as the organizing foundation of political action, and therefore, as strategic and potentially subversive to the AIc. Whether strategic or not, this "stealth mode" may nevertheless be understood as generating a form of what Tsing refers to as "contaminated diversity" (p. 29), which "changes the work we imagine for names, including ethnicities and species" (p. 29), and, we would argue, identities vis-a-vis ontological constructs such as autistic and non-autistic. What is the "work" of "autism" in terms of identification? What might contamination (e.g., erasure of a binary) of autistic with allistic mean?

The latter of these examples of evading the apparatus of the AIC (i.e., operating "off-grid") is an increasingly common experience for a widening range of people. By this we mean autistic people who build lives and who thrive in the "ruins" — not seeking diagnosis, paperwork, intervention or accommodation, but a space wherein they might live and thrive without reference to such constructs. These are the people who make their living and build their community in asynchronous, digital, non-centralized, and gig-based economies, or in flexible employment such as computer science and other analytic fields where autistic experience is an asset rather than a liability. These are the autistic children thriving in free-range, unschooling/ deschooling/homeschooling networks, developing their talents, interests, and strengths without reference to a schooling system that sees them as fundamentally deficient and in need of fixing (i.e., becoming, or at least appearing, less autistic). There is precarity in this, yes, but precarity, as Tsing points out to us, is increasingly endemic to contemporary lived experience. Curiosity about these ways of living in subversion of or without reference to the AIC might be what she calls "the first requirement of collaborative survival in precarious times" (p. 2). And we are living in precarious times.

\section{References}

Albrecht, G. L. (1992). The disability business. SAGE.

Broderick, Alicia. (2009). Autism, "recovery [to normalcy]" and the politics of hope. Intellectual and Developmental Disability, 47, 263-281.

Broderick, Alicia. (2010). Autism as enemy: Metaphor and cultural politics. In Leonardo, Zeus (ed.), Handbook of Cultural Politics and Education, pp. 237-268. Rotterdam: Sense Publishers. 
Broderick, Alicia. (2011). Autism as rhetoric: Exploring watershed rhetorical moments. Disability Studies Quarterly, 31(3): n.p.. http://www.dsq-sds.org/article/ view/1674/1597" http://www.dsq-sds.org/article/view/1674/1597

Broderick, Alicia. (2017, March). Autism as enemy (metaphor) in service of intervention as industry (narrative): The symbiotic production of the autism industrial complex. Paper presented at Look Both Ways: Narrative and Metaphor in Education Conference, 30 March - 1 April, 2017. Vrije Universiteit, Amsterdam, The Netherlands.

Broderick, Alicia. (forthcoming). Autism, Inc.: The Autism Industrial Complex. Gorham, ME: Myers Education Press.

Broderick, Alicia \& Ari Ne'eman. (2008). Autism as metaphor: Narrative and counternarrative. International Journal of Inclusive Education, 12 (5-6): 459-476.

Broderick, Alicia \& Robin Roscigno. (2019, November). Autism, inc.: The autism industrial complex. Paper presented at American Educational Studies Association Annual Conference, 30 October-2 November, 2019. Baltimore, MD.

Behavior Analyst Certification Board. (n.d.). BACB certificant data. Retrieved October 17, 2018, from https://www.bacb.com/bacb-certificant-data/.

Buescher, A. V. S., Cidav, Z., Knapp, M., \& Mandell, D. S. (2014). Costs of Autism Spectrum Disorders in the United Kingdom and the United States. JAMA Pediatrics, 168(8), 721-728. https://doi.org/10.10o1/jamapediatrics.2014.210.

Bumiller, K. (2013). Caring for autism: Towards a more responsive state. In M. Orsini \& J. Davidson (Eds.), Worlds of Autism: Accross the Spectrum of Neurological Difference. Univ. Of Minnesota Press. https://doi.org/10.5749/ minnesota/978o816688883.003.0007.

Davidson, J., \& Orsini, M. (2013). Worlds of autism. https://doi.org/10.5749/ minnesota/9780816688883.001.00o1.

Dawson, M. (2004). The misbehavior of behaviourists: Ethical challenges to the autism/ ABA industry. https://www.sentex.ca/ nexus23/naa_aba.html

Ehrenreich, B., \& Ehrenreich, J. (1970). The medical-industrial complex. NY Review of Books, 14.

Eyal, G. (2010). The Autism Matrix. Polity.

Goodley, D. (2016). Autism and the Human. In Re-thinking autism: Diagnosis, identity and equality (pp. 146-159). Jessica Kingsly Publishers.

Grinker, R. (2018). Who owns autism? Economics, fetishism and stakeholders. In E. Fein \& C. Rios (Eds.), Autism in translation: An intercultural conversation on autism spectrum conditions. Palgrave MacMillan.

Grinker, R. R. (2020). Autism, "stigma," disability: A shifting historical terrain. Current Anthropology, 61(S21), S55-S67. https://doi.org/10.1086/705748.

Hacking, I. (1999). The social construction of what? Harvard University Press.

Harvey, D. D. (2003). The new imperialism. 
Helt, M., Kelley, E., Kinsbourne, M., Pandey, J., Boorstein, H., Herbert, M., \& Fein, D. (2008). Can children with autism recover? If so, how? Neuropsychology Review, 18(4), 339-366. https://doi.org/10.1007/s11065-0o8-9075-9.

Jack, J. (2014). Autism and gender: From refrigerator mothers to computer geeks. University of Illinois Press.

Latif, S. (2016). The ethics and consequences of making autism spectrum diagnoses. In K. Runswick-Cole, R. Mallett, \& S. Timimi (Eds.), Rethinking Autism: Diagnosis, Identity and Equality. Jessica Kingsley Publishers.

Leigh, J. P., \& Du, J. (2015). Brief report: Forecasting the economic burden of autism in 2015 and 2025 in the United States. Journal of Autism and Developmental Disorders, 45(12), 4135-4139. https://doi.org/10.1007/s10803-015-2521-7.

Longmore, P. K. (2016). Telethons: Spectacle, disability, and the business of charity. Oxford University Press.

Mallett, R., \& Runswick-Cole, K. (2012). Commodifying autism: The cultural contexts of 'disability' in the academy. In D. Goodley, B. Hughes, \& L. Davis (Eds.), Disability and Social Theory: New Developments and Directions (pp. 33-51). Palgrave Macmillan. https://doi.org/10.1057/9781137023001_3.

Mallett, R., \& Runswick-Cole, K. (2016). The commodification of autism: What's at stake? In Katherine Runswick-Cole, Rebecca Mallett, \& Sami Timimi (Eds.), Re-thinking autism. Jessica Kingsly Publishers.

McGuire, A. (2016). War on autism: On the cultural logic of normative violence. University of Michigan Press.

McGuire, A. E. (2013). Buying time: The s/pace of advocacy and the cultural production of autism. Canadian Journal of Disability Studies, 2(3), 98. https://doi.org/10.15353/ cjds.v2i3.102.

Milton, D., \& Moon, L. (2012). The normalisation agenda and the psycho-emotional disablement of autistic people. Autonomy, the Critical Journal of Interdisciplinary Autism Studies, 1(1).

Mingus, M. (2015, February 6). Medical industrial complex visual. Leaving Evidence. https://leavingevidence.wordpress.com/2015/o2/o6/medical-industrial-complexvisual/.

Mitchell, D. T., \& Snyder, S. L. (2015). The biopolitics of disability: Neoliberalism, ablenationalism, and peripheral embodiment. University of Michigan Press.

Murray, S. (2012). Autism. Routledge.

Nadesan, M. H. (2005). Constructing autism (1 edition). Routledge.

Nadesan, M. H. (2013). Autism and genetics: Profit, risk, and bare life. In M. Orsini \& J. Davidson (Eds.), Worlds of autism: Across the spectrum of neurological difference. Univ Of Minnesota Press.

Osteen, M. (2010). Autism and representation. Routledge. 
Persons with a disability: Labor force characteristiscs - 2019 (USDL-20-0339; p. 11). (2020). Bureau of Labor Statistics, United States Department of Labor. www.bls.gov/cps.

Picciano, A. G., \& Spring, J. (2012). The great American education-industrial Complex (1 edition). Routledge.

Rodas, J. M. (2018). Autistic disturbances: Theorizing autism poetics from the DSM to Robinson Crusoe. University of Michigan Press.

Roscigno, R. (2019). Neuroqueerness as Fugitive Practice: Reading Against the Grain of Applied Behavior Analysis Scholarship, Educational Studies, 55:4, 405-419.

Roscigno, R. (2020). Semiotic stalemate: Resisting restraint and seclusion through Guattari's micropolitics of desire, Canadian Journal of Disability Studies, 9(5), 155184. DOI: https://doi.org/10.15353/cjds.v9i5.694.

Rosenthal, K., \& Rosenthal, K. (Eds.). (2019). Capitalism and disability: Selected writings by Marta Russell. Haymarket Books.

Runswick-Cole, K., Mallett, R., \& Timimi, S. (Eds.). (2016). Re-thinking autism:Diagnosis, identity and equality. Jessica Kingsley Publishers.

Sequenzia, A. (2016). Autistic conversion therapy. Autistic Women \& Nonbinary Network $(A W N)$. https://awnnetwork.org/autistic-conversion-therapy/.

Silberman, S. (2015). Neurotribes: The legacy of autism and the future of neurodiversity. Penguin.

Silverman, C. (2013). Understanding autism: Parents, doctors, and the history of a disorder. Princeton University Press.

Timimi, S., \& McCabe, B. (2016). Autism screening and diagnostic tools. In K. RunswickCole, R. Mallett, \& S. Timimi (Eds.), Re-thinking autism: Diagnosis, identity and equality. Jessica Kingsley Publishers.

Tsing, A. L. (2015). The mushroom at the end of the world: On the possibility of life in capitalist ruins. https://doi.org/10.1017/CBO9781107415324.004.

Wang, J. (2018). Carceral Capitalism. Semiotext.

Yergeau, M. (2017). Authoring autism. Duke University Press. https://doi. org/10.1215/9780822372189. 